\title{
The impact of ice uptake of nitric acid on atmospheric chemistry
}

\author{
R. von Kuhlmann ${ }^{1, *}$ and M. G. Lawrence ${ }^{1}$ \\ ${ }^{1}$ Max-Planck-Institute for Chemistry, Department of Airchemistry, Mainz \\ *now at: German Aerospace Center (DLR), Bonn
}

Received: 21 June 2005 - Published in Atmos. Chem. Phys. Discuss.: 24 August 2005

Revised: 5 December 2005 - Accepted: 12 December 2005 - Published: 27 January 2006

\begin{abstract}
The potential impact of the uptake of $\mathrm{HNO}_{3}$ on ice on the distribution of $\mathrm{NO}_{\mathrm{y}}$ species, ozone and $\mathrm{OH}$ has been assessed using the global scale chemistry-transport model MATCH-MPIC. Assuming equilibrium uptake according to dissociative Langmuir theory results in significant reductions of gas phase $\mathrm{HNO}_{3}$. Comparison to a large set of observations provides support that significant uptake of $\mathrm{HNO}_{3}$ on ice is occurring, but the degree of the uptake cannot be inferred from this comparison alone. Sensitivity simulations show that the uncertainties in the total amount of ice formation in the atmosphere and the actual expression of the settling velocity of ice particles only result in small changes in our results. The largest uncertainty is likely to be linked to the actual theory describing the uptake process and the value of the initial uptake coefficient. The inclusion of non-methane hydrocarbon chemistry partially compensates for the absence of $\mathrm{HNO}_{3}$ uptake on ice when this is neglected in the model. The calculated overall effect on upper tropospheric ozone concentrations and the tropospheric methane lifetime are moderate to low. These results support a shift in the motivation for future experimental and theoretical studies of $\mathrm{HNO}_{3}$-ice interaction towards the role of $\mathrm{HNO}_{3}$ in hydrometeor surface physics.
\end{abstract}

\section{Introduction}

A large fraction of the loss of reactive nitrogen $\left(\mathrm{NO}_{\mathrm{y}}\right)$ in the atmosphere occurs via scavenging of nitric acid $\left(\mathrm{HNO}_{3}\right)$ by clouds. Nitrogen oxides $\left(\mathrm{NO}_{\mathrm{x}}=\mathrm{NO}+\mathrm{NO}_{2}\right)$, important precursors of ozone $\left(\mathrm{O}_{3}\right)$ and the hydroxyl radical $(\mathrm{OH})$, can therefore be strongly affected by this process. $\mathrm{HNO}_{3}$ has also recently been found to influence the growth of aerosols and cloud droplets (Nenes et al., 2002), and has been hypothe-

Correspondence to: R. von Kuhlmann

(rolf.vonkuhlmann@dlr.de) sized to affect ice crystals (Gao et al., 2004). Besides PAN, $\mathrm{HNO}_{3}$ is an important reservoir species of $\mathrm{NO}_{\mathrm{y}}$ (e.g. Neuman et al., 2001; Staudt et al., 2003), thus capable of transporting odd nitrogen into remote regions. A small direct radiative effect of $\mathrm{HNO}_{3}$ has also been calculated (Evans and Puckrin, 2001); however, this is probably only of significance in highly polluted areas (up to $0.2 \mathrm{~W} / \mathrm{m}^{2}$ under those conditions).

During the last few years a large number of laboratory studies (Zondlo et al., 1997; Abbatt, 1997; Arora et al., 1999; Hudson et al., 2002; Hynes et al., 2002; Ullerstam et al., 2005; Ullerstam and Abbatt, 2005) and field observations (e.g. Weinheimer et al., 1998; Meilinger et al., 1999; Kondo et al., 2003; Popp et al., 2004; Ziereis et al., 2004) have investigated the uptake of $\mathrm{HNO}_{3}$ on ice particles and have led to significant advances in the understanding of this process. However, until recently laboratory conditions were mostly different from those typically found in the atmosphere, and, combined with experimental uncertainties and natural variability, still render our knowledge of a generally applicable theory of the uptake process and its global importance incomplete. Also, different pathways of ice formation in the atmosphere - riming and diffusional growth - and the particle growth history in the dynamically changing environment (Kärcher and Basko, 2004; Ullerstam and Abbatt, 2005) complicate the situation.

Assuming efficient uptake rates on ice, Lawrence and Crutzen (1998) found a significant redistribution of $\mathrm{HNO}_{3}$ by gravitational settling of ice particles resulting in reduced mixing ratios in the upper troposphere (UT). Tabazadeh et al. (1999) proposed applying dissociative Langmuir theory to the uptake process and suggested that the assumptions used in Lawrence and Crutzen (1998) probably resulted in too efficient uptake.

Using the formulation of Tabazadeh et al. (1999) in a box model, Meier and Hendricks (2002) assessed the chemical effects in the UT and instead found significant impacts for

(C) 2006 Author(s). This work is licensed under a Creative Commons License. 
Table 1. Short descriptions and acronyms of the sensitivity simulations.

\begin{tabular}{|c|c|}
\hline Experiment & Description \\
\hline NOUP & No uptake of $\mathrm{HNO}_{3}$ on ice surfaces. \\
\hline HIGHUP & $\begin{array}{l}\text { Efficient uptake of } \mathrm{HNO}_{3} \text { on ice as in von } \\
\text { Kuhlmann et al. (2003a). }\end{array}$ \\
\hline LANGM & Dissoc. Langmuir uptake, $\Delta \mathrm{H}_{\mathrm{ads}}=-44 \mathrm{~kJ} / \mathrm{mol}$ \\
\hline LANGM2 & $\begin{array}{l}\text { As LANGM, but } \Delta \mathrm{H}_{\mathrm{ads}}=-59.4 \mathrm{~kJ} / \mathrm{mol} \\
\text { (Tabazadeh et al., 1999) }\end{array}$ \\
\hline VHEYMS & $\begin{array}{l}\text { As LANGM, but using an expression of ice set- } \\
\text { tling velocity from Heymsfield (2003). }\end{array}$ \\
\hline LESSICE & $\begin{array}{l}\text { As LANGM, but } \approx 1 / 3 \text { IWC (Rasch and } \\
\text { Kristjánsson, 1998). }\end{array}$ \\
\hline CH4NOUP & As NOUP, but not including NMHC chemistry. \\
\hline CH4HIGH & $\begin{array}{l}\text { As HIGHUP, but not including NMHC chem- } \\
\text { istry. }\end{array}$ \\
\hline
\end{tabular}

some scenarios. Both studies, however, emphasize that the potential effects on a larger scale still have to be assessed with a 3-D model, which is the aim of this study.

Thus far, Liao et al. (2003) have incorporated an 0.3 monolayer uptake of $\mathrm{HNO}_{3}$ on ice particles in their general circulation model and report an increase in zonal mean gasphase $\mathrm{HNO}_{3}$ of up to a factor of 2 when leaving out this process. Effects on other species, however, where not reported. Lawrence and Crutzen (1998) specifically focused on the effects of gravitational settling using simple assumptions about $\mathrm{HNO}_{3}$ uptake. Here, we take a broader perspective and investigate the general effect of ice uptake on atmospheric chemistry using more elaborate uptake formulations, an extended chemistry scheme and a larger suite of observations. The influence of non-methane hydrocarbon (NMHC) chemistry on the calculated effects, which was neglected in Lawrence and Crutzen (1998), will also be investigated.

\section{Model setup}

We employ the global chemistry-transport model MATCHMPIC (Model of Atmospheric Transport and Chemistry, Max-Planck-Institute for Chemistry version) (Rasch et al., 1997; Lawrence et al., 1999; von Kuhlmann et al., 2003a, and references therein) at a resolution of about $5.6^{\circ} \times 5.6^{\circ}(\mathrm{T} 21)$, with 28 vertical levels and a time step of $0.5 \mathrm{~h}$. The model is driven by NCEP/NCAR reanalysis data (Kalnay et al., 1996). The model treats grid-scale advective transport, convection, vertical mixing, settling of ice particles, wet and dry deposition and chemical transformations of ozone and 55 related species, including non-methane hydrocarbons ( $\leq \mathrm{C} 4$ and isoprene) through 144 reactions. Heterogeneous chemistry is only included in the case of hydrolysis of $\mathrm{N}_{2} \mathrm{O}_{5}$ on aerosols and cloud droplets to form $\mathrm{HNO}_{3}$ (Dentener and Crutzen, 1993).

As part of continuing model development we have updated the reaction rates (mainly to Sander et al., 2003) and the chemical mechanism. A detailed listing of all reactions is given in the supplementary material (http://www. atmos-chem-phys.org/acp/6/225/acp-6-225-sp.pdf). For example, photolysis channels of $\mathrm{HNO}_{4}$ in the near-IR have been included according to Roehl et al. (2002). The global lightning source strength used here is about $2 \mathrm{Tg}-\mathrm{N} / \mathrm{yr}$ and is distributed in the vertical according to Pickering et al. (1998). Other sources are implemented as described in von Kuhlmann et al. (2003a). Recent thorough comparisons of the model to observations of a large suite of trace gases have been presented by von Kuhlmann et al. (2003a,b); Lawrence et al. (2003) and Labrador et al. (2005). The version used here displays very similar characteristics as presented in these studies. While the distributions of $\mathrm{O}_{3}$ and $\mathrm{CO}$ were generally well captured by the model, larger deviations were found in some nitrogen species. PAN was often overestimated in the remote UT, $\mathrm{HNO}_{3}$ often underestimated at all altitudes compared to measurements. The regions where the underestimate of $\mathrm{HNO}_{3}$ occur are often far away from direct surface sources (e.g., in the tropical Pacific), thus pointing towards too efficient washout in the model.

A number of sensitivity runs, listed in Table 1, were performed. For each case a simulation was run through 16 months (1 September 1995-31 December 1996) initialized with a September distribution from an earlier model run, and only the results for 1996 were used.

The case HIGHUP follows the approach previously used in MATCH-MPIC (von Kuhlmann et al., 2003a) which describes the uptake of $\mathrm{HNO}_{3}$ analogous to Henry's Law, thus implicitly allowing for bulk uptake.

In the other experiments a dissociative Langmuir model as in Tabazadeh et al. (1999) is applied. Thus, we iteratively include the effect of $\mathrm{HNO}_{3}$ depletion on the coverage and also allow only a maximum coverage of $0.27 \cdot 10^{15} \mathrm{molec} / \mathrm{cm}^{2}$ to better match the data of Abbatt (1997).

Different from previous studies, calculation of the equilibrium constant is done using a reference laboratory value from Hynes et al. (2002) in order to avoid large uncertainties in the pre-exponential factors in the adsorption rate. It is assumed that equilibrium is reached in each time step, computed as

$K_{\text {eq }}=K_{\text {ref }} \cdot \exp \left[\frac{-\Delta H_{\text {ads }}}{R}\left(\frac{1}{T}-\frac{1}{T_{\text {ref }}}\right)\right]$,

where $\quad K_{\text {ref }}=6.77 \cdot 10^{4}$ Torr $^{-1}, \quad T_{\text {ref }}=228 \mathrm{~K} \quad$ and $\Delta H_{\mathrm{ads}}=-44 \mathrm{~kJ} / \mathrm{mol}$ (Bartels-Rausch et al., 2002) ( $\mathrm{R}$ is the universal gas constant). The value of $\Delta H_{\text {ads }}$ determined by Bartels-Rausch et al. (2002) is used here because their determination did not rely on a particular theory of the uptake process. In good agreement to this, Popp et al. (2004) empirically derive from field observations 


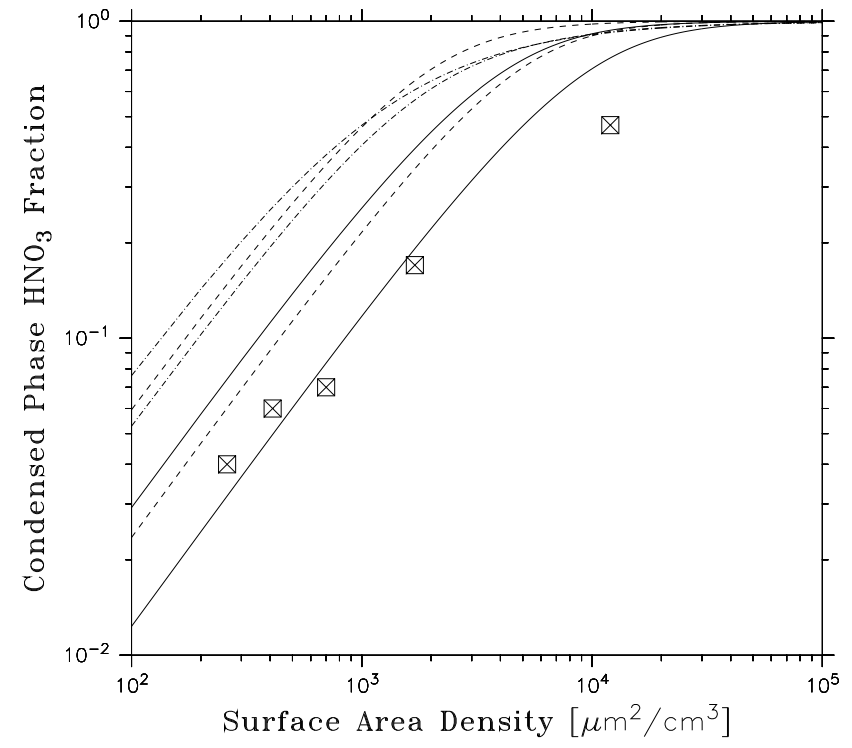

Fig. 1. Fraction of total $\mathrm{HNO}_{3}$ predicted by the model formulation to be in the condensed phase. Three pairs of one thick and thin line are shown, corresponding to $100 \mathrm{pmol} / \mathrm{mol}$ and $500 \mathrm{pmol} / \mathrm{mol}$ of total $\mathrm{HNO}_{3}$, respectively. Solid lines are for dissociative Langmuir theory using Eq. (1) at $214 \mathrm{~K}$, dashed lines the same but for $200 \mathrm{~K}$. The dash-dotted lines represent non-dissociative Langmuir theory and $\mathrm{K}_{\mathrm{eq}}$ at $214 \mathrm{~K}$ according to Ullerstam et al. (2005). Symbols indicate quintiles of the data of Popp et al. (2004).

(CRYSTAL-FACE) a value of $46 \mathrm{~kJ} / \mathrm{mol}$ for the adsorbtion enthalpy. They note, however, that this cannot to be taken as a fundamental thermodynamic parameter. However, because we calculate $\mathrm{K}_{\mathrm{eq}}$ based on the measurements by Hynes et al. (2002) (at $228 \mathrm{~K}$ ) our values for $\mathrm{K}_{\mathrm{eq}}$ and thus for the uptake are on average higher than observed by Popp et al. (2004) (see Fig. 1). Popp et al. (2004) also tested the multi-layer Frenkel-Halsey-Hill (FHH) model as proposed by Hudson et al. (2002), but found less good agreement for temperatures below $205 \mathrm{~K}$, where the FHH model overestimated the coverage compared to the measurements, though large scatter of a factor of 5 was also found in the observations.

Recently, Ullerstam et al. (2005) performed laboratory measurements under nitric acid partial pressures found in the upper troposphere. They found that a non-dissociative uptake law described their data better and provide an expression for $\mathrm{K}_{\mathrm{eq}}$ between 214 and $239 \mathrm{~K}$. Using this expression, however, would lead to a larger overstimate of the fractional $\mathrm{HNO}_{3}$ coverage compared to the data of Popp et al. (2004) (see dash-dotted lines in Fig. 1).

The surface area density (SAD) of ice clouds and their mean settling velocity are parameterized based on the calculated ice water content (IWC) as in Lawrence and Crutzen (1998) based on measurements during the Central Equatorial Pacific Experiment (CEPEX).

$\mathrm{SAD}\left[\mathrm{cm}^{2} / \mathrm{cm}^{3}\right]=2 \cdot 10^{-4} \times \operatorname{IWC}\left[\mathrm{g} / \mathrm{m}^{3}\right]^{0.9}$,
Table 2. Integrated annual mean tropospheric and upper tropospheric $(\mathrm{p}<500 \mathrm{hPa})$ tracer masses using the monthly mean diagnosed tropopause and monthly mean tracer fields. Absolute values are in $\operatorname{Tg}\left(\mathrm{O}_{3}\right)$ for ozone and $\mathrm{Gg}(\mathrm{N})$ otherwise. Percent changes of $\mathrm{CH} 4 \mathrm{HIGH}$ are with respect to the CH4NOUP scenario, otherwise changes are with respect to the NOUP simulation.

\begin{tabular}{|c|c|c|c|c|}
\hline & $\mathrm{HNO}_{3}$ & $\mathrm{NO}_{\mathrm{x}}$ & PAN & $\mathrm{O}_{3}$ \\
\hline & \multicolumn{4}{|c|}{ Troposphere } \\
\hline NOUP & 173 & 141 & 362 & 339 \\
\hline HIGHUP & $-37 \%$ & $-6.3 \%$ & $-2.6 \%$ & $-3.9 \%$ \\
\hline LANGM & $-24 \%$ & $-4.4 \%$ & $-1.7 \%$ & $-2.7 \%$ \\
\hline LANGM2 & $-23 \%$ & $-4.5 \%$ & $-1.6 \%$ & $-2.7 \%$ \\
\hline VHEYMS & $-24 \%$ & $-4.5 \%$ & $-1.7 \%$ & $-2.8 \%$ \\
\hline LESSICE & $-13 \%$ & $-5.6 \%$ & $-6.1 \%$ & $-4.2 \%$ \\
\hline CH4NOUP & 215 & 146 & - & 296 \\
\hline \multirow[t]{2}{*}{ CH4HIGH } & $-49 \%$ & $-13 \%$ & - & $-7.1 \%$ \\
\hline & \multicolumn{4}{|c|}{ Upper Troposphere } \\
\hline NOUP & 69 & 66 & 196 & 180 \\
\hline HIGHUP & $-70 \%$ & $-15.6 \%$ & $-4.3 \%$ & $-4.9 \%$ \\
\hline LANGM & $-49 \%$ & $-11.8 \%$ & $-3.3 \%$ & $-3.5 \%$ \\
\hline LANGM2 & $-47 \%$ & $-11.9 \%$ & $-3.2 \%$ & $-3.5 \%$ \\
\hline VHEYMS & $-49 \%$ & $-12.0 \%$ & $-3.3 \%$ & $-3.6 \%$ \\
\hline LESSICE & $-36 \%$ & $-11.1 \%$ & $-7.7 \%$ & $-4.8 \%$ \\
\hline CH4NOUP & 111 & 78 & - & 165 \\
\hline CH4HIGH & $-76 \%$ & $-25 \%$ & - & $-7.6 \%$ \\
\hline
\end{tabular}

where $\mathrm{SAD}$ is in $\mathrm{cm}^{2} / \mathrm{cm}^{3}$ and IWC is in $\mathrm{g} / \mathrm{m}^{3}$. Thus, we assume a conservative value of 2 for the conversion factor from cross sectional area to surface area. It is noted that Popp et al. (2004) have found significantly higher surface area densities for a given IWC (see their Fig. 9b). The impact of this difference is further discussed in Sect. 3.3.

A maximum value for the settling velocity of $100 \mathrm{~cm} / \mathrm{s}$ is applied to avoid unreasonably large values for very large IWCs (Lawrence and Crutzen, 1998).

The main differences between the model used by Liao et al. (2003) and MATCH is that Liao et al. (2003) include more aerosol/gas interactions (in MATCH only hydrolysis of $\mathrm{N}_{2} \mathrm{O}_{5}$ on sulphate aerosols is included), whereas this study treats $\mathrm{HNO}_{3}$-ice interactions in a more sophisticated way.

\section{Results and discussion}

\subsection{Effects on $\mathrm{HNO}_{3}$}

The general effect of the globally integrated tracer masses of $\mathrm{HNO}_{3}, \mathrm{O}_{3}, \mathrm{NO}_{\mathrm{x}}$ and PAN is summarized in Table 2. Since the largest differences occur in the upper troposphere, total masses and changes for this region are also calculated. In the standard dissociative Langmuir uptake simulation (LANGM) a strong depletion of $\mathrm{HNO}_{3}$ in the UT is calculated (Fig. 2). 

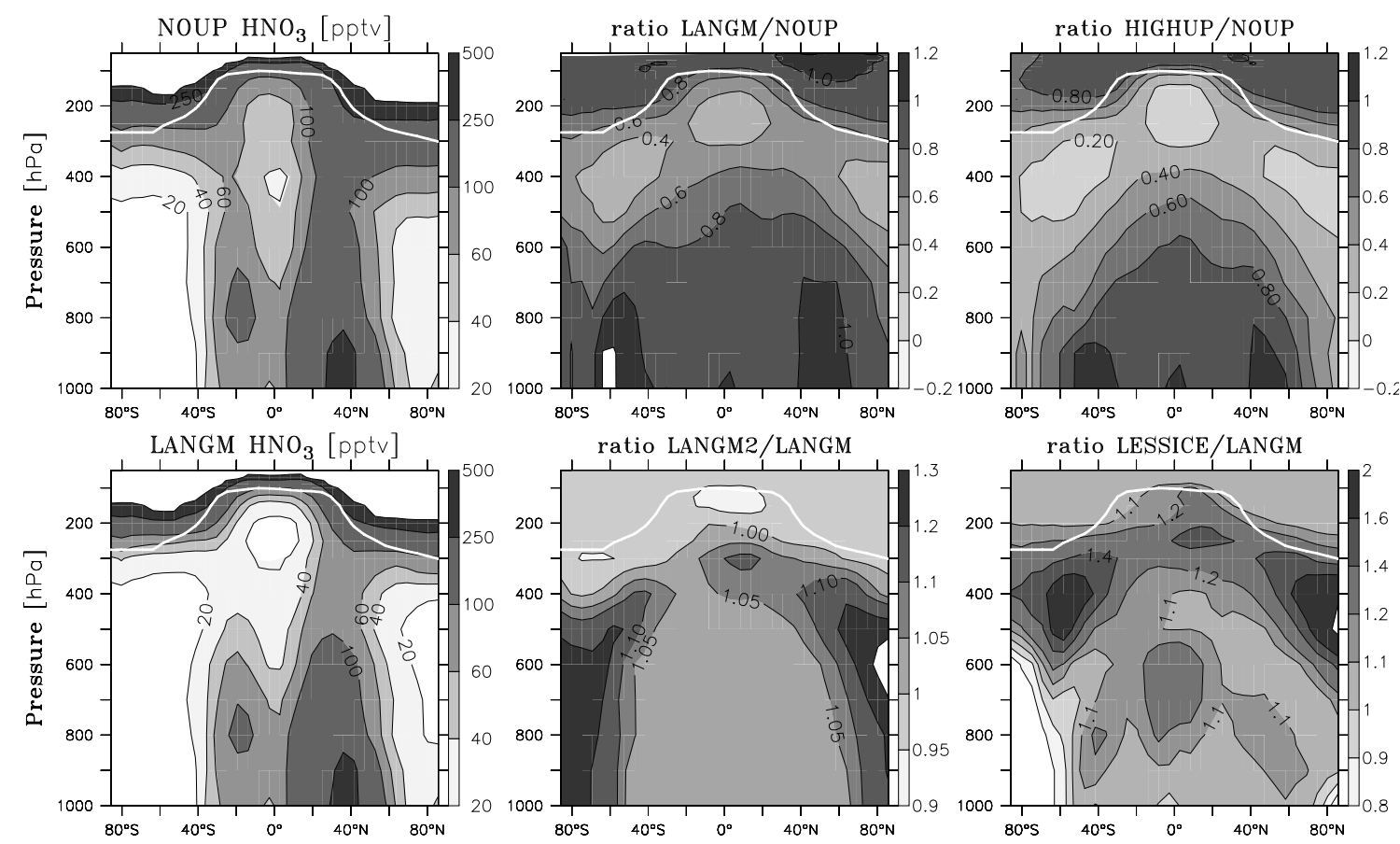

Fig. 2. Annual zonal mean $\mathrm{HNO}_{3}$ from the NOUP and LANGM runs (left) and ratios of the LANGM and HIGHUP simulation to the run without uptake on ice (first row). Scenarios LANGM2 and LESSICE are compared to the LANGM run in the second row. The white line indicates the model tropopause.

The maximum effect (HIGHUP/NOUP) is also shown in Fig. 2. It is found that in the Langmuir uptake scenario already about $2 / 3$ of the maximum effect is calculated. This is also reflected in integrated $\mathrm{HNO}_{3}$ tracer masses in Table 2: The LANGM scenario results in $49 \%$ less $\mathrm{HNO}_{3}$ in the upper troposphere on the annual average and in $70 \%$ less $\mathrm{HNO}_{3}$ in the HIGHUP case compared to a simulation where uptake on ice is neglected (NOUP). The effects on tropospheric $\mathrm{HNO}_{3}$ masses are still $-24 \%$ and $-37 \%$ for the LANGM and HIGHUP scenarios, respectively.

These results are different than the small effect expected by Tabazadeh et al. (1999) based on simple consideration for monodisperse ice clouds. A likely reason lies in their assumptions of a monodisperse size distribution and a constant IWC $\left(=25 \mathrm{mg} / \mathrm{m}^{3}\right)$. These assumptions combined actually reverse the positive correlation of SAD with mean settling velocity implicit in the observed positive correlation of IWC with SAD (Heymsfield and McFarquhar, 1996) and of IWC with the mean settling velocity (e.g. Heymsfield, 2003). Meier and Hendricks (2002) have also calculated significant reductions in their box-model scenarios, though using higher initial $\mathrm{HNO}_{3}$ mixing ratios than generally found in MATCHMPIC.

The calculated IWC contents were evaluated by Lawrence and Crutzen (1998) and found to be in good agreement with observations of Heymsfield and McFarquhar (1996). However, in view of the large scatter in the observations, a sensitivity simulation (LESSICE) has been performed in which the globally averaged ice water path has been reduced from 57 to $19 \mathrm{~g} / \mathrm{m}^{2}$ (LESSICE) as in Rasch and Kristjánsson (1998). In the LESSICE simulation the overall reduction of $\mathrm{HNO}_{3}$ is smaller, resulting in a larger tropospheric mass of $44 \mathrm{Gg}(\mathrm{N})$ compared to 35 in the LANGM case, but the reduction of zonal mean $\mathrm{HNO}_{3}$ still reaches $60 \%$ or more compared to the NOUP run. Compared to the LANGM run $\mathrm{HNO}_{3}$ levels are higher especially in the upper troposphere by about $20 \%-60 \%$ (Fig. 2, lower right panel). The strong relative effect seen in polar regions is from cold temperatures and small overall $\mathrm{HNO}_{3}$ levels there.

To test the sensitivity to the chosen temperature dependence in our formulation of the uptake a simulation using $\Delta H_{\text {ads }}=-59 \mathrm{~kJ} / \mathrm{mol}$ from Tabazadeh et al. (1999) is performed (LANGM2). In the zonal means moderate changes can be found (e.g. from about $-5 \%$ to $+10 \%$ in tropical and subtropical regions, see Fig. 2, lower middle panel). As expected, in the cold uppermost tropical troposphere a decrease of $\mathrm{HNO}_{3}$ is found in the LANGM2 simulation as the larger value of $\Delta H_{\text {ads }}$ leads to more efficient uptake at lower temperatures, but to less efficient uptake at higher temperatures. However, the integrated effects on $\mathrm{HNO}_{3}$ are very small (Table 2). Comparison of in-situ observations (e.g. Popp et al., 2004) allow a larger range of $K_{e q}$ and thus this test is not intended to cover the full range of uncertainty in the uptake. This larger range in the observations also indicates that a 
large uncertainty lies in the formulation of the theoretical model actually appropriate to describe the uptake process and possibly points towards a significant role for dynamic growth effects (Kärcher and Basko, 2004; Ullerstam and Abbatt, 2005).

Another uncertainty lies in the vertical settling process. A new parameterization for the mean terminal fall velocity $\left(\mathrm{V}_{s}\right.$ in $\left.\mathrm{cm} / \mathrm{s}\right)$ of ice crystals has been derived by Heymsfield (2003):

$V_{s}=165 \cdot \mathrm{IWC}^{0.24}-10$,

where IWC is in $\mathrm{g} / \mathrm{m}^{3}$. The expression applies to all latitudes. The last term is to account for a difference between the mass and (cross sectional) area weighted mean fall velocity which may be more appropriate here and is only applied for IWC $>0.01 \mathrm{~g} / \mathrm{m}^{3}$. The maximum value allowed was increased to $140 \mathrm{~cm} / \mathrm{s}$ (Heymsfield, 2003, see their Fig. 11c) for this simulation (VHEYMS). This expression yields larger values for larger IWC compared to the expression used by Lawrence and Crutzen (1998) (e.g., $+28 \mathrm{~cm} / \mathrm{s}$ or $+30 \%$ for an IWC of $0.4 \mathrm{~g} / \mathrm{cm}^{3}$ ). However, a test simulation using this relation only results in a few percent change in zonal mean $\mathrm{HNO}_{3}$ compared to the LANGM case. The biggest change is found in the uppermost tropical troposphere, where up to $8 \%$ less $\mathrm{HNO}_{3}$ (stronger denitrification) is found in the VHEYMS simulation due to faster fall velocities. Below this region a small $(<3 \%)$ increase in $\mathrm{HNO}_{3}$ is calculated (not shown). This result also implies that the small difference between mass and (cross sectional) area weighted mean fall velocities is probably of minor importance in redistributing $\mathrm{HNO}_{3}$. However, the larger effects found for the LESSICE simulation suggests that this may be because the LANGM case is already largely depleted in $\mathrm{HNO}_{3}$. Therefore, despite the small difference found here, the expression above is recommended for future studies due to the larger underlying database.

As can be seen in Table 2, all three sensitivity simulations to the standard Langmuir model (LANGM) result in only small changes in globally integrated masses of $\mathrm{HNO}_{3}$ and other key species.

\subsection{Effects on other species}

The maximum effects on $\mathrm{NO}_{\mathrm{y}}$ species other than $\mathrm{HNO}_{3}$ are also noticable but smaller (Table 2). Zonal mean mixing ratios of $\mathrm{NO}_{\mathrm{x}}$ and PAN are decreased by up to $20 \%$ and $5 \%$, respectively, in HIGHUP compared to the NOUP case ( $-15.6 \%$ and $-4.3 \%$ in terms of integrated UT masses). As expected the effect maximizes above $300 \mathrm{hPa}$ in the tropics. For the tropical pacific region Staudt et al. (2003) also performed a sensitivity simulation assuming $100 \%$ scavenging by ice clouds and compared their results to data from the PEM-Tropics A and B campaigns also included in our comparison. The effects of switching from inefficient to effective scavenging in their study is somewhat less pronounced for
$\mathrm{HNO}_{3}$ and $\mathrm{NO}_{\mathrm{x}}$ than found here. Possibly this is related to the fact that gravitational settling of non-precipitating cloud particles was not included in that study. In the upper troposphere of the Pacific warm pool region the relative effects for $\mathrm{HNO}_{3}$ are strongest, up to a factor of 10 reduction (see e.g. Fig. 6, PEM-West-A: Phillipine-Sea region). Thus, if an influence of $\mathrm{HNO}_{3}$ on surface hydrometeor physics (as e.g. in Gao et al. (2004)) can be established, the overall degree of uptake into the condensed phases would be very important for these processes.

On the other hand, we calculate that two important aspects of atmospheric chemistry and climate interactions, namely ozone in the UT as a greenhouse gas and the oxidizing efficiency of the atmosphere, are only weakly perturbed by uptake of $\mathrm{HNO}_{3}$ on ice. In particular, zonal mean ozone concentrations are reduced by less than $7 \%$ when efficient uptake (HIGHUP) is switched on (Fig. 3). The differences between the other scenarios are even smaller (e.g., $-4 \%$ for the LANGM scenario). The tropospheric mean methane lifetime (as a measure of the oxidizing efficiency) changes only by $3 \%$ between the HIGHUP and NOUP scenarios, since the largest changes are in the UT where the reaction rate for methane oxidation is slower.

\subsection{Discussion of uncertainties}

There are several aspects of the model formulation and experimental uncertainties which could affect these estimates. We assume that equilibrium between gas and condensed phase is reached during each $30 \mathrm{~min}$ timestep. While this propably leads to some overstimation of the uptake, implementing a kinetic limitation would result in an underestimation because all $\mathrm{HNO}_{3}$ is transferred back into the gas phase for the computation of advection.

To gauge the severity of this overestimate we have calculated the $\mathrm{HNO}_{3}$ lifetime for typical particle size discributions (PSD) based on parameterizations derived by Heymsfield (2003, see their Fig. 3). In the calculation, limitations due to the diffusion to the particle, as well as the interfacial transport, expressed by the uptake coefficient $\gamma$, are taken into account. A spherical geometry is assumed for the ice particles. For typical ice clouds (at $218 \mathrm{~K}$ and $150 \mathrm{hPa}$ ) with IWCs of $50 \mathrm{mg} / \mathrm{m}^{3}$ and $15 \mathrm{mg} / \mathrm{m}^{3}$, and a SAD of 1900 and $600 \mu \mathrm{m}^{2} / \mathrm{cm}^{3}$, respectively, $\mathrm{HNO}_{3}$ lifetimes of 7 and 19 minutes are calculated. The diffusion limitation contributes about one third to these lifetimes. If $\gamma=0.01$ is assumed, the lifetimes for these cases increase to $20 \mathrm{~min}$ and about $1 \mathrm{~h}$, respectively. Assuming $\gamma=0.001$ yields about 2 and $6 \mathrm{~h}$, respectively.

There is considerable disagreement concerning the initial uptake coefficient of $\mathrm{HNO}_{3}$ on ice surfaces. Uptake is generally found efficient $(\gamma \geq 0.1)$ for temperatures below about $200 \mathrm{~K}$, but for higher temperatures several authors report values between 0.001 and 0.01 , in disagreement to Ullerstam et al. (2005) who recently reported $\gamma \geq 0.1$ for temperatures 

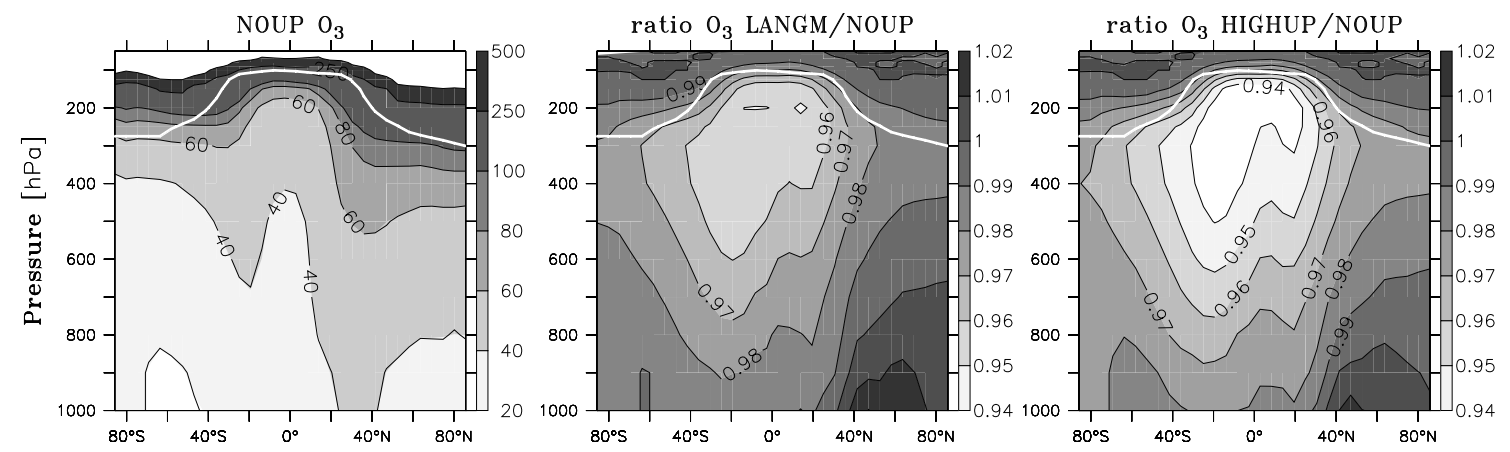

Fig. 3. Annual zonal mean $\mathrm{O}_{3}$ from the NOUP run and ratios of the LANGM and HIGHUP simulation to the run without uptake on ice. The white line indicates the model tropopause.

as high as $239 \mathrm{~K}$. The calculations above show that for $\gamma>0.01$ the equilibrium approach leads only to significant overstimated uptake of $\mathrm{HNO}_{3}$ for thin ice clouds which, however, do not lead to strong vertical redistribution through settling. If most ice clouds typically persist for several hours the overestimate in our approach should be small. This, however, assumes that the individual ice particle lifetime and the cirrus lifetime are comparable, which may not be the case (Barth et al., 2003). If, however, $\gamma \approx 0.001$, the equilibrium approach would lead to significantly overestimated effects of ice clouds on $\mathrm{HNO}_{3}$ even for clouds with high SAD. Further studies to improve the experimental determination of this parameter are therefore necessary.

Another aspect to keep in mind is that ice particle mass is not only created via diffusional growth of small initial particles, but also through contact freezing of supercooled liquid droplets (riming), mainly in the upper part of convective clouds. Experimental and theoretical studies by Iribarne and Pyshnov (1990) and Stuart and Jacobson (2003) have suggested that most $\mathrm{HNO}_{3}$ is probably retained during the freezing process. Neglecting to differentiate these pathways should therefore tend to underestimate the overall uptake of $\mathrm{HNO}_{3}$ on ice particles. However, a global quantification of the relative importance of these ice formation pathways has not been attempted yet, and the effects on $\mathrm{HNO}_{3}$ can therefore not be quantified easily.

The adsorption of $\mathrm{HNO}_{3}$, as well as other gases, in the atmosphere takes place in a dynamic environment. The effect of burial of trace gases during growth of the ice crystals was theoretically described by Kärcher and Basko (2004). They calculate that trapping of $\mathrm{HNO}_{3}$ could take place even at low ice supersaturations. Recently, Ullerstam and Abbatt (2005) found significantly enhanced uptake of $\mathrm{HNO}_{3}$ in laboratory experiments under ice growth conditions compared to ice surfaces at equilibrium (i.e. 100\% relative humidity). However, Ullerstam and Abbatt (2005) state that in light of discrepancies between their findings and the current model formulation by Kärcher and Basko (2004) and also because fundamental parameters are not well constrained, the knowl- edge of this process is still incomplete. Furthermore, including such dynamic growth effects in a 3-D modelling framework is not straightforward, as unknown assumptions about different formation conditions of ice particles and the associated fluctuations in temperature and water vapour would have to be made. Therefore, these effects should be further studied in box models before a global extrapolation is attempted. However, neglecting this enhanced uptake in our simulations may lead to an underestimated trace gas uptake in our simulations.

Uncertainties also exist in the simulated ice amounts and in the calculated surface areas. As noted in Sect. 2, Popp et al. (2004) during the CRYSTAL-FACE campaign have found up to a factor of 10 higher SADs for a given IWC than calculated by Eq. (2). It is unclear if this difference reflects the large natural variability or if experimental issues or additional assumptions are different. A part of the difference may be explained by a larger ratio between cross sectional and surface area of the particles used by Lawrence and Crutzen (1998). For small ice crystals, which dominate the surface area, a spherical shape is a good approximation (see e.g. Heymsfield et al., 2002). The ratio of surface to cross-section for spheres is only a factor of 2 larger than the one used by Lawrence and Crutzen (1998) (4 versus 2). Therefore, this can likely only explain part of the difference. We have recalculated the SAD-to-IWC relation assuming a spherical shape by integrating over typical PSDs from Heymsfield (2003) and could reproduce within a factor of 2 the relationship in Eq. (2) used here. Although we cannot resolve this issue at present, it demonstrates the need for more data on ice cloud PSDs.

The range of effects tested in this study - from no uptake to quasi-Henry's Law bulk uptake (NOUP, HIGHUP) - should, nevertheless, bracket these uncertainties, with the exception of uncertainties in global SADs,

\subsection{Comparison to observations}

In search of observational evidence concering the interaction of $\mathrm{HNO}_{3}$ and ice clouds, the model results have been 


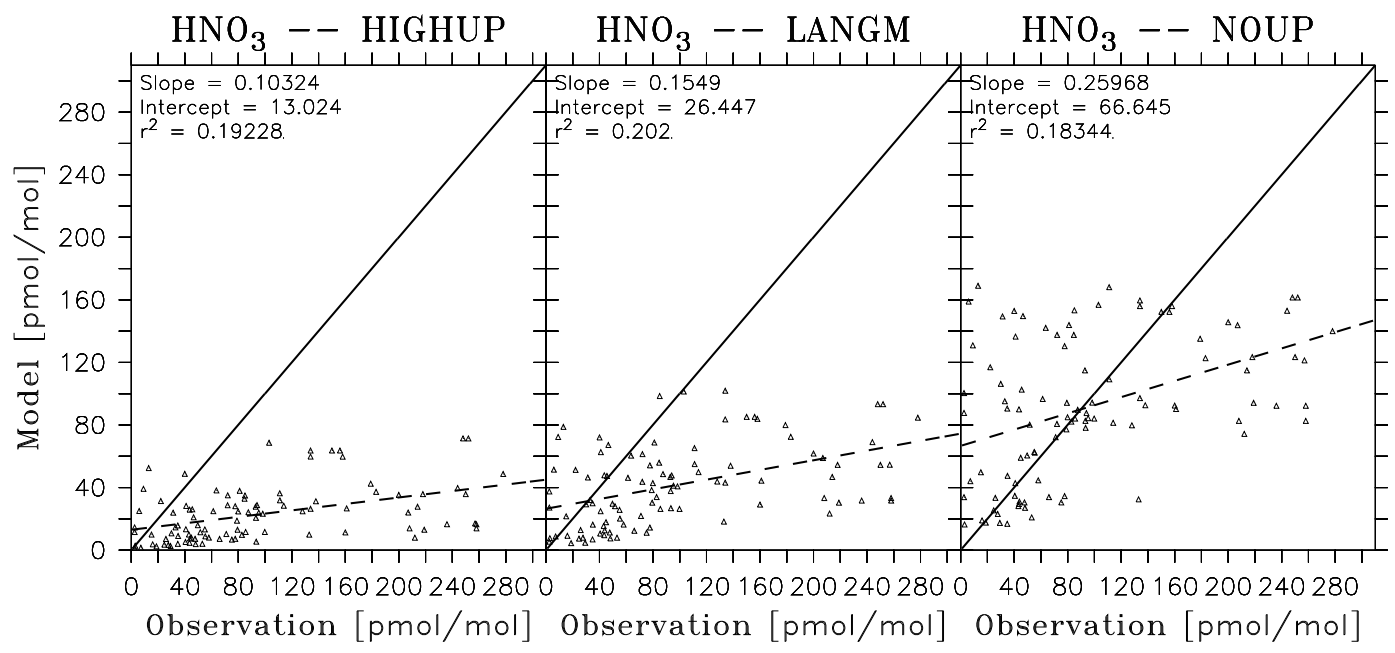

Fig. 4. Scatter plot of simulated monthly means versus regionally merged campaign profiles from Emmons et al. (2000) using all data above $8 \mathrm{~km}$ altitude for the HIGHUP, LANGM and NOUP runs. The dashed line is the linear regression line through the data.

compared to a large suite of campaign data taken mainly from Emmons et al. (2000), but also including more recent campaigns (TRACE-P, TOPSE, PEM-Tropics B). Monthly mean model data are compared to regionally merged profile data collected in different years. Comparison of large scale model data with point measurements have some inherent problems which need to be acknowledged. This is especially the case for $\mathrm{HNO}_{3}$, for which a major loss process (wet deposition) is expected to be strongly heterogeneously distributed on the sub-grid scale. Therefore, we focus on main features that appear in the comparison and not on individual campaign results, and particularly on a statistical analysis.

51 regional profiles with $1 \mathrm{~km}$ vertical resolution merged from campaign data (Emmons et al., 2000) have been compared to the monthly mean modeled profiles in the same regions. Figure 4 shows scatter plots of the mean modeled values for each height interval above $8 \mathrm{~km}$ in each case versus the observed values. Only data above $8 \mathrm{~km}$, where the largest effect would be expected, are plotted. Examples of individual profiles are discussed below and the full set of profile plots is provided in the supplement (http://www.atmos-chem-phys. org/acp/6/225/acp-6-225-sp.pdf). A general underestimate of modelled $\mathrm{HNO}_{3}$ is found in the scenario with efficient uptake, consistent with von Kuhlmann et al. (2003b). If uptake on ice is switched off a large number of cases where the model strongly overestimates the observations is seen, yet some high mixing ratios are still underestimated. It can also be seen that the simulation applying Langmuir uptake is already very effectively reducing $\mathrm{HNO}_{3}$. The same scatter plot is shown for the mid-troposphere (4-8 km) in Fig. 5. Again, a tendency of the model to underestimate large measured values can be seen. In the mid-troposphere the simulation without any uptake of $\mathrm{HNO}_{3}$ appears to produce the smallest bias compared to observations. However, this is likely due to compensating effects. As found in von Kuhlmann et al. (2003b), MATCH-MPIC generally tends to underestimate $\mathrm{HNO}_{3}$ in the lower and mid-troposphere. Since this region is not expected to be strongly influenced by ice cloud, this is likely due to reasons not related to the treatement of ice-uptake. Scavenging by liquid cloud particles, unknown chemistry or underestimated sources are possible explanations.

As mentioned above, not too much weight should be given to each individual campaign comparison, due to the methodology of our comparison (using monthly means of one particular year). On the other hand, in comparisons with single or few measurement campaigns using the actual meteorological situation, correct (sub-grid) spatial sampling is still an issue and the results are more prone to errors in the representation of the meteorology during the campaign. Ideally, a statistical analysis of many campaigns using the spatially and temporaly interpolated model values should be performed (Brunner et al., 2003). However, performing several (multi-year) sensitivity simulations with this setup goes beyond the scope of this study. Nevertheless, inspecting the full ensemble of 51 regional comparisons (see the supporting online material: http://www.atmos-chem-phys.org/acp/6/ 225/acp-6-225-sp.pdf) can bring some insight.

The fact that in many cases, especially in remote regions with aged airmasses, there often is a general underestimation by the model, suggests that this might be due to other factors not related to ice affecting $\mathrm{HNO}_{3}$ in the mid and lower troposphere, likely (liquid) precipitation scavenging (Velders and Granier, 2001). The formulation of wet scavenging used here is based on Henry's Law equilibrium which is assumed to be reached each time-step. This neglect of kinetic limitations in the gas uptake could lead to a general overestimation of scavenging of highly soluble gases. 


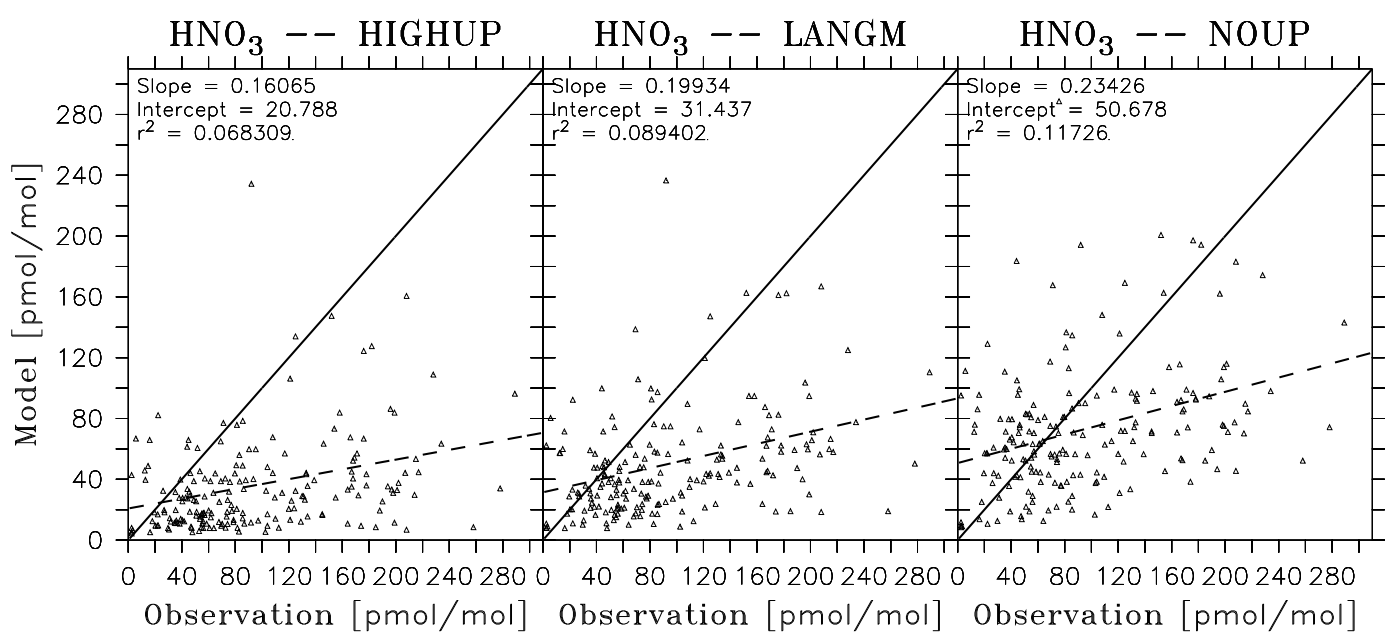

Fig. 5. Same as Fig. 4, but for the measurement and model in the height intervall $4-8 \mathrm{~km}$.

The general picture of the regional comparison is illustrated by a few example profile comparisons in Fig. 6. Often, when the model underestimates $\mathrm{HNO}_{3}$ throughout the troposphere, not allowing for uptake on ice improves the comparison in the UT (left panel), while in many cases $\mathrm{HNO}_{3}$ is not underestimated significantly, and in these cases the NOUP scenario often overestimates observations in the UT (right panel). Generally these individual profiles also show that a straightforward interpretation is not possible due to large scatter in the data and without analyzing the model representation of the meteorology for each campaign. An intermediate scenario, like the Langmuir uptake run (LANGM), would be expected to compare best. However, this is not apparant from the calculated statistics of the comparison (e.g., $\mathrm{r}^{2}=0.20$ for LANGM).

It is noted that a tendency to underestimate high values is typical of this kind of comparison since a 3-D model is more averaged, both spatially and temporally, than the campaign data (von Kuhlmann et al., 2003b) and often campaign flights are targetting pollution plumes. Also, it cannot be ruled out that other factors such as gas/aerosol partitioning (Liao et al., 2003) have a strong influence on gas phase nitric acid concentrations. Thus, although there are many clear overestimates in the NOUP case none of the Langmuir uptake scenarios can be judged best based on this comparison. More measurements, in particular in the tropical UT, would be valuable to reach firmer conclusions.

\subsection{Effects of non-methane hydrocarbons}

How strongly are the results shown so far influenced by the inclusion of NMHCs, not present in Lawrence and Crutzen (1998)? To answer this the two extreme cases (without and including efficient uptake) have been repeated without NMHC chemistry (CH4NOUP and CH4HIGH). These are representative of the BASE and STDFALL runs in Lawrence and Crutzen (1998). In Table 2 it can be seen that the relative effect of the uptake is stronger in the simulations without NMHCs. This is mainly due to the additional important $\mathrm{NO}_{\mathrm{y}}$ reservoir species peroxy acetylnitrate (PAN) which results from NMHC oxidation and reduces the availability of $\mathrm{HNO}_{3}$ in the UT (compare $\mathrm{HNO}_{3} / \mathrm{NO}_{\mathrm{x}}$ ratios in NOUP and CH4NOUP), and thus its additional loss through vertical redistribution. The supply of $\mathrm{NO}_{\mathrm{x}}$ through long-range transport of PAN and its thermal decomposition provides an alternative pathway to $\mathrm{NO}_{\mathrm{x}}$ and subsequently $\mathrm{HNO}_{3}$ in the remote troposphere. This more direct link from a decrease in $\mathrm{HNO}_{3}$ to a decrease in $\mathrm{NO}_{\mathrm{x}}$ causes the $25 \%$-reduction of $\mathrm{NO}_{\mathrm{x}}$ in $\mathrm{CH} 4 \mathrm{HIGH}$ simulation compared to its baseline, whereas in the HIGHUP run the reduction is only $16 \%$. Therefore, also the effects on ozone are more pronounced in the $\mathrm{CH} 4$ runs (7.6\% change in the global tropospheric burden). Thus, the effects of a more realistic Langmuir uptake scenario in this study should be less pronounced than if it were tested using the model-setup of Lawrence and Crutzen (1998).

\section{Conclusions}

We have assessed the potential impact of the uptake of $\mathrm{HNO}_{3}$ on ice particles on the tropospheric concentrations of $\mathrm{NO}_{\mathrm{y}}$ species, ozone and $\mathrm{OH}$ using the global model MATCHMPIC. Using a dissociative Langmuir equilibrium model for the uptake and through sensitivity simulations the following main points are brought out:

- Dissociative Langmuir theory for the uptake process results in a significant reduction of $\mathrm{HNO}_{3}$ in the upper troposphere, in contrast with Tabazadeh et al. (1999) but in basic agreement with Meier and Hendricks (2002).

- Neglecting the uptake results in a large number of striking overestimates of $\mathrm{HNO}_{3}$ compared to observations 


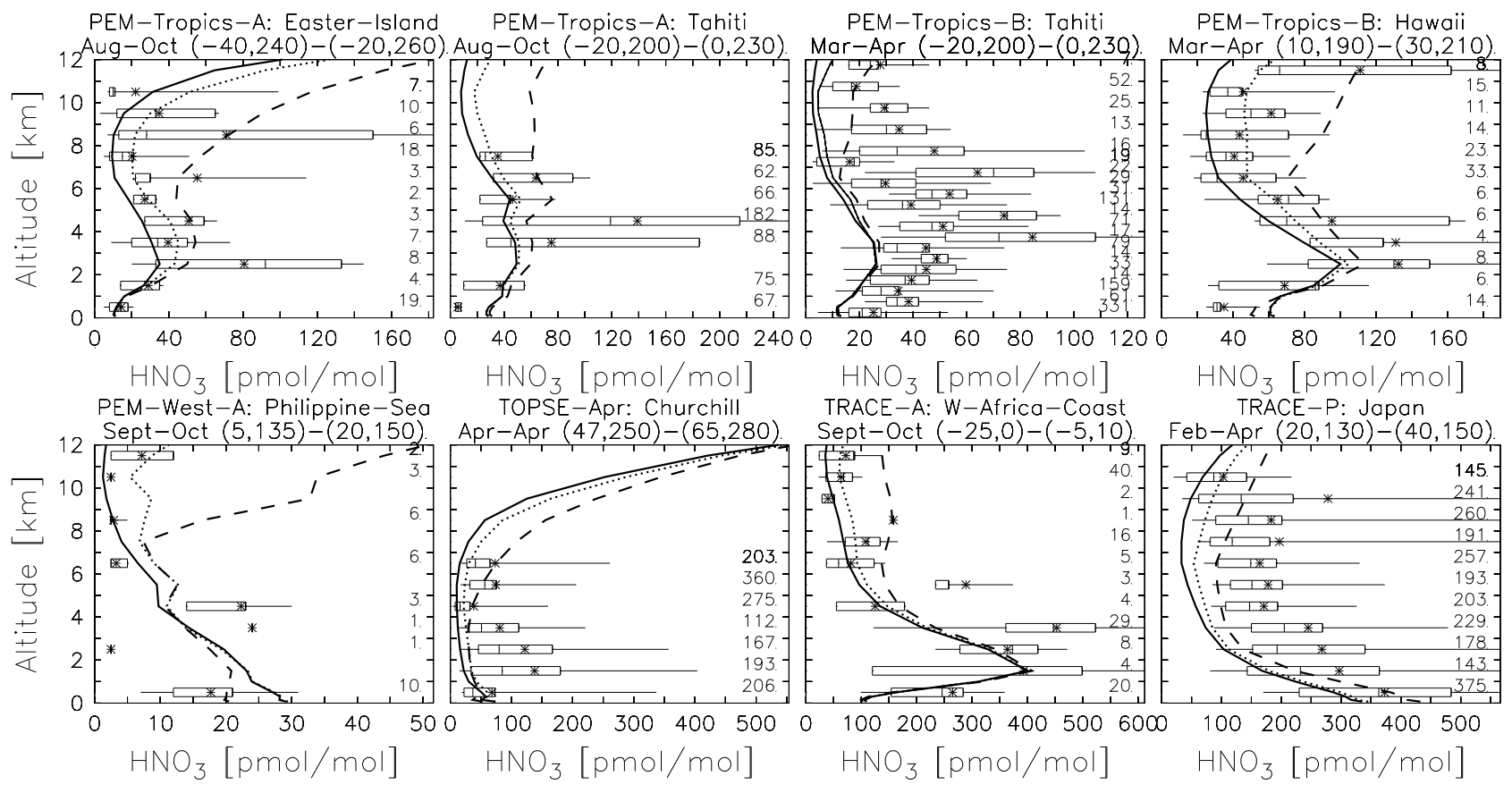

Fig. 6. Comparison of regional vertical profiles of $\mathrm{HNO}_{3}$ to model output. Solid, dotted and dashed lines are for the HIGHUP, LANGM, and NOUP simulations, respectively. Boxes, whiskers, horizontal line and asterix mark the central 50 and 90\%, median and mean of the observations, respectively. The number of observations at each altitude interval is given to the right. In region "Tahiti" (PEM-Tropics B) measurements from two platforms (DC8 and P3) are shown in the upper and lower parts of the $1 \mathrm{~km}$ intervals.

despite a general tendency of the model to underestimate $\mathrm{HNO}_{3}$.

- However, due to large scatter and other uncertain factors in the comparison, no best uptake rate can be deduced based on this comparison.

- More measurements of ice water content and surface area densities are needed to better constrain the model fields.

- Clarification of the value of the initial uptake coefficient at temperatures above $200 \mathrm{~K}$ is necessary as it could make uptake of $\mathrm{HNO}_{3}$ inefficient for short-lived ice clouds or if individual particle lifetimes are less than about a few hours.

- NMHC chemistry buffers the effect on $\mathrm{HNO}_{3}$ and on other gases, by providing PAN as an alternative $\mathrm{NO}_{\mathrm{y}}$ reservoir species.

- While local effects on $\mathrm{HNO}_{3}$ can be strong, they only translate into moderate to small overall effects on global tropospheric $\mathrm{O}_{3}$ and the oxidation efficiency of the troposphere. However, the effects of $\mathrm{HNO}_{3}$ taken up by hydrometeors or aerosols on surface physics may be much more important.

While inclusion of a best guess of the uptake effects based on current knowledge is nevertheless recommended for in- clusion in atmospheric chemistry models, the effect of remaining uncertainties on ozone and the oxidation efficiency are probably small compared to other issues.

An untested chemical issue remains the possibility of reactions on the ice surface, such as the photolysis of the nitrate radical (e.g. Honrath et al., 1999, 2000; Zhou et al., 2003). Although a recent study by Chu and Anastasio (2003) have judged the latter process to be of minor importance, further evidence is needed. Moreover, these points suggest that a stronger emphasis should be placed on investigations of the impact of $\mathrm{HNO}_{3}$ on surface hydrometeor physics (e.g. Gao et al., 2004), which could have a significant influence on cirrus formation, lifetime and albedo, and thus on the radiative effects of cirrus clouds.

Acknowledgements. The authors thank C. Winkler, J. Crowley and M. Salzmann for valuable discussions, L. Emmons for providing recent regionally merged data files and P. Rasch for MATCH support. Funding by the German Ministry of Education and Research (BMBF), project 07-ATC-02, is gratefully acknowledged.

Edited by: J. N. Crowley

\section{References}

Heymsfield, A. J., Bansemer, P. R. F., Durden, S. L., Stith, J. L., Dye, J. E., Hall, W., and Grainger, C. A.: Observations and Parameterization of Particle Size Distributions in Deep Tropical 
Cirrus and Stratiform Precipitating Clouds: Results from In Situ Observations in TRMM Field Campaigns, J. Atmos. Chem., 59, 3457-3491, 2002.

Abbatt, J. P. D.: Interaction of $\mathrm{HNO}_{3}$ with water-ice surfaces at temperatures of the free troposphere, Geophys. Res. Lett., 24, 1479-1482, 1997.

Arora, O. P., Cziczo, D. J., Morgan, A. M., Abbatt, J. P. D., and Niedziela, R. F.: Uptake of nitric acid by sub-micron-sized ice particles, Geophys. Res. Lett., 26, 3621-3624, 1999.

Bartels-Rausch, T., Eichler, B., Zimmermann, P., Gäggeler, H. W., and Ammann, M.: The adsorption enthalpy of nitrogen oxides on crystalline ice, Atmos. Chem. Phys., 2, 235-247, 2002,

SRef-ID: 1680-7324/acp/2002-2-235.

Barth, M. C., Sillman, S., Hudman, R., Jacobson, M. Z., Kim, C. H., Monod, A., and Liang, J.: Summary of the cloud chemistry modeling intercomparison: Photochemical box model simulation, J. Geophys. Res., 108, 4214, doi:10.1029/2002JD002673, 2003.

Brunner, D., Staehelin, J., Rogers, H. L., Köhler, M. O., Pyle, J. A., Hauglustaine, D., Jourdain, L., Berntsen, T. K., Gauss, M., Meijer, I. S. A. I. E., van Velthoven, P., Pitari, G., Mancini, E., Grewe, V., and Sausen, R.: An evaluation of the performance of chemistry transport models by comparison with research aircraft observations. Part 1: Concepts and overall model performance, Atmos. Chem. Phys., 3, 1609-1631, 2003,

\section{SRef-ID: 1680-7324/acp/2003-3-1609.}

Chu, L. and Anastasio, C.: Quantum Yields of Hydroxyl Radical and Nitrogen Dioxide from the Photolysis of Nitrate on Ice, J. Phys. Chem. A, 107, 9594-9602, 2003.

Dentener, F. J. and Crutzen, P. J.: Reaction of $\mathrm{N}_{2} \mathrm{O}_{5}$ on Tropospheric Aerosols: Impact on the Global Distributions of $\mathrm{NO}_{\mathrm{x}}$, $\mathrm{O}_{3}$, and $\mathrm{OH}, \mathrm{J}$. Geophys. Res., 98, 7149-7163, 1993.

Emmons, L. K., Hauglustaine, D. A., Müller, J.-F., Carroll, M. A., Brasseur, G. P., Brunner, D., Staehelin, J., Thouret, V., and Marenco, A.: Data composites of airborne observations of tropospheric ozone and its precursors, J. Geophys. Res., 105, $20497-$ $20538,2000$.

Evans, W. F. J. and Puckrin, E.: The surface radiative forcing of Nitric Acid for northern mid-latitudes, Atmos. Environ., 35, 7177, 2001.

Gao, R. S., Popp, P. J., Fahey, D. W., Marcy, T. P., Herman, R. L., Weinstock, E. M., Baumgardner, D. G., Garrett, T. J., Rosenlof, K. H., Thompson, T. L., Bui, P. T., Ridley, B. A., Wofsy, S. C., Toon, O. B., Tolbert, M. A., Kärcher, B., Peter, T., Hudson, P. K., Weinheimer, A. J., and Heymsfield, A. J.: Evidence That Nitric Acid Increases Relative Humidity in Low-Temperature Cirrus Clouds, Science, 303, 516-520, 2004.

Heymsfield, A. J.: Properties of Tropical and Midlatitude Ice Cloud Particle Ensembles. Part II: Applictions for Mesoscale and Climate Models, J. Atmos. Chem., 60, 2592-2611, 2003.

Heymsfield, A. J. and McFarquhar, G. M.: High albedos of cirrus in the tropical pacific warm pool: Microphysical interpretations from CEPEX and from Kwajalein, Marshall Islands, J. Atmos. Chem., 53, 2424-2451, 1996.

Honrath, R. E., Peterson, M. C., Guo, S., Dibb, J. E., Shepson, P. B., and Campbell, B.: Evidence of $\mathrm{NO}_{\mathrm{x}}$ production with or upon ice particles in the Greenland Snowpack, Geophys. Res. Lett., 26, 695-698, 1999.

Honrath, R. E., Guo, S., Peterson, M. C., Dziobak, M. P., Dibb, J. E., and Arsenault, M. A.: Photochemical production of gas phase $\mathrm{NO}_{\mathrm{X}}$ from ice crystal $\mathrm{NO}_{3}^{-}$, J. Geophys. Res., 105, $24183-$ 24 190, 2000.

Hudson, P. K., Shilling, J. E., Tolbert, M. A., and Toon, O. B.: Uptake of Nitric Acid on Ice at Tropospheric Temperatures: Implications for Cirrus Clouds, J. Phys. Chem. A, 106, 9874-9882, 2002.

Hynes, R. G., Fernandez, M. A., and Cox, R. A.: Uptake of $\mathrm{HNO}_{3}$ on water-ice and coadsorption of $\mathrm{HNO}_{3}$ and $\mathrm{HCl}$ in the temperature range 210-235 K, J. Geophys. Res., 107, 4797, doi:10.1029/2001JD001557, 2002.

Iribarne, J. V. and Pyshnov, T.: The effect of freezing on the composition of supercooled droplets - I. Retention of $\mathrm{HCl}, \mathrm{HNO}_{3}$, $\mathrm{NH}_{3}$, and $\mathrm{H}_{2} \mathrm{O}_{2}$, Atmos. Environ., 24A, 383-387, 1990.

Kalnay, E., Kanamitsu, M., Kistler, R., Collins, W., Deaven, D., Gandin, L., Iredell, M., Saha, S., White, G., Woollen, J., Zhu, Y., Chelliah, M., Ebisuzaki, W., Higgins, W., Janowiak, J., Mo, K., Ropelewski, C., Wang, J., Leetmaa, A., Reynolds, R., Jenne, R., and Joseph, D.: The NCEP/NCAR 40-year reanalysis project, Bull. Am. Meteorol. Soc., 77, 437-471, 1996.

Kärcher, B. and Basko, M. M.: Trapping of trace gases in growing ice crystals, J. Geophys. Res., 109, D22 204, 10.1029/2004JD005254, 2004.

Kondo, Y., Toon, O. B., Irie, H., Gamblin, B., Koike, M., Takegawa, N., Tolbert, M. A., Hudson, P. K., Viggiano, A. A., Avallone, L. M., Hallar, A. G., Anderson, B. E., Sachse, G. W., Vay, S. A., Hunton, D. E., Ballenthin, J. O., and Miller, T. M.: Uptake of reactive nitrogen on cirrus cloud particles in the upper troposphere and lowermost stratosphere, Geophys. Res. Lett., 30, 1154, doi:10.1029/2002GL016539, 2003.

Labrador, L. J., von Kuhlmann, R., and Lawrence, M. G.: The effects of lightning-produced $\mathrm{NO}_{\mathrm{x}}$ and its vertical distribution on atmospheric chemistry: sensitivity simulations with MATCHMPIC, Atmos. Chem. Phys., 5, 1815-1834, 2005,

SRef-ID: 1680-7324/acp/2005-5-1815.

Lawrence, M. G. and Crutzen, P. J.: The impact of cloud particle gravitational settling on soluble trace gas distributions, Tellus, 50B, 263-289, 1998.

Lawrence, M. G., Crutzen, P. J., Rasch, P. J., Eaton, B. E., and Mahowald, N. M.: A model for studies of tropospheric photochemistry: Description, global distributions, and evaluation, J. Geophys. Res., 104, 26 245-26277, 1999.

Lawrence, M. G., Rasch, P. J., von Kuhlmann, R., Williams, J., Fischer, H., de Reus, M., Lelieveld, J., Crutzen, P. J., Schultz, M., Stier, P., Huntrieser, H., Heland, J., Stohl, A., Forster, C., Elbern, H., Jakobs, H., and Dickerson, R. R.: Global chemical weather forecasts for field campaign planning: predictions and observations of large-scale features during MINOS, CONTRACE, and INDOEX, Atmos. Chem. Phys., 3, 267-289, 2003,

SRef-ID: 1680-7324/acp/2003-3-267.

Liao, H., Adams, P. J., Chung, S. H., Seinfeld, J. H., Mickley, L. J., and Jacob, D. J.: Interactions between tropospheric chemistry and aerosols in a unified general circulation model, J. Geophys. Res., 108, 4001, doi:10.1029/2001JD001260, 2003.

Meier, A. and Hendricks, J.: Model studies on the sensitivity of upper tropospheric chemistry to heterogeneous uptake of $\mathrm{HNO}_{3}$ on cirrus ice particles, J. Geophys. Res., 107, 4696, doi:10.1029/2001JD000735, 2002.

Meilinger, S. K., Tsias, A., Dreiling, V., Kuhn, M., Feigl, C., Ziereis, H., Schlager, H., Curtius, J., Sierau, B., Arnold, F., 
Zöger, M., Schiller, C., and Peter, T.: $\mathrm{HNO}_{3}$ Partitioning in Cirrus Clouds, Geophys. Res. Lett., 26, 2207-2210, 1999.

Nenes, A., Charlson, R. J., Facchini, M. C., Kulmala, M., Laaksonen, A., and Seinfeld, J. H.: Can chemical effects on cloud droplet number rival the first indirect effect?, Geophys. Res. Lett., 29, 1848, doi:10.1029/2002GL015295, 2002.

Neuman, J. A., Gao, R. S., Fahey, D. W., Holecek, J. C., Ridley, B. A., Walega, J. G., Grahek, F. E., Richard, E. C., McElroy, C. T., Thompson, T. L., Elkins, J. W., Moore, F. L., and Ray, E. A.: In situ measurements of $\mathrm{HNO}_{3}, \mathrm{NO}_{\mathrm{y}}, \mathrm{NO}$, and $\mathrm{O}_{3}$ in the lower stratosphere and upper troposhere, Atmos. Environ., 35, 57895797, 2001.

Pickering, K. E., Wang, Y., Tao, W. K., Price, C., and Müller, J.F.: Vertical distributions of lightning $\mathrm{NO}_{\mathrm{x}}$ for use in regional and global chemical transport models, J. Geophys. Res., 103, 31203 $31216,1998$.

Popp, P. J., Gao, R. S., Marcy, T. P., Fahey, D. W., Hudson, P. K., Thompson, T. L., Kärcher, B., Ridley, B. A., Weinheimer, A. J., Knapp, D. J., Montzka, D. D., Baumgardner, D., Garrett, T. J., Weinstock, E. M., Smith, J. B., Sayres, D. S., Pittman, J. V., Dhaniyala, S., Bui, T. P., and Mahoney, M. J.: Nitric Acid Uptake on Subtropical Cirrus Cloud Particles, J. Geophys. Res., 109, D06 302, doi: 10.1029/2003JD004255, 2004.

Rasch, P. J. and Kristjánsson, J. E.: A comparison of the CCM3 model climate using diagnosed and predicted condensate parameterizations, J. Climate, 11, 1587-1614, 1998.

Rasch, P. J., Mahowald, N. M., and Eaton, B. E.: Representations of transport, convection and the hydrologic cycle in chemical transport models: Implications for the modeling of short lived and soluble species, J. Geophys. Res., 102, 28 127-28 138, 1997.

Roehl, C. M., Nizkorodov, S. A., Zhang, H., Blake, G. A., and Wennberg, P. O.: Photodissociation of Peroxynitric Acid in the Near-IR, J. Phys. Chem. A, 106, 3766-3772, 2002.

Sander, S. P., Friedl, R. R., Ravishankara, A. R., Golden, D. M., Kolb, C. E., Kurylo, M. J., Huie, R. E., Orkin, V. L., Molina, M. J., Moortgat, G. K., and Finlayson-Pitts, B. J.: Chemical Kinetics and Photochemical Data for Use in Atmospheric Studies, Evaluation Number 14, 02-25, Jet Propulsion Laboratory, Pasadena, California, 2003.

Staudt, A. C., Jacob, D. J., Ravetta, F., Logan, J. A., Bachiochi, D., Krishnamurti, T. N., Sandholm, S., Ridley, B., Singh, H. B., and Talbot, B.: Sources and chemistry of nitrogen oxides over the tropical pacific, J. Geophys. Res., 108, 8239, doi:10.1029/2002JD002139, 2003.
Stuart, A. L. and Jacobson, M. Z.: A timescale investigation of volatile chemical retention during hydrometeor freezing: Nonrime freezing and dry growth riming without spreading, J. Geophys. Res., 108, 4178, doi:10.1029/2001JD001408, 2003.

Tabazadeh, A., Toon, O. B., and Jensen, E. J.: A surface chemistry model for nonreactive trace gas adsorption on ice: Implications for nitric acid scavenging by cirrus, Geophys. Res. Lett., 26, 2211-2214, 1999.

Ullerstam, M. and Abbatt, J. P. D.: Burial of gas-phase $\mathrm{HNO}_{3}$ by growing ice surfaces under tropospheric conditions, Phys. Chem. Chem. Phys., 7, 3596-3600, 2005.

Ullerstam, M., Thornberry, T., and Abbatt, J. P. D.: Uptake of gasphase nitric acid to ice at low partial pressures: evidence for unsaturated surface coverage, Faraday Discuss., 130, 211-226, doi:10.1039/b41718f, 2005.

Velders, G. J. M. and Granier, C.: Sensitivity of washout on $\mathrm{HNO}_{3} / \mathrm{NO}_{x}$ ratio in atmospheric chemistry transport models, J. Geophys. Res., 106, 3125-3132, 2001.

von Kuhlmann, R., Lawrence, M. G., Crutzen, P. J., and Rasch, P. J.: A model for studies of tropospheric ozone and nonmethane hydrocarbons: Model description and ozone results, J. Geophys. Res., 108, 4294, doi:10.1029/2002JD002893, http: //www.mpch-mainz.mpg.de/ kuhlmann/matcheval, 2003a.

von Kuhlmann, R., Lawrence, M. G., Crutzen, P. J., and Rasch, P. J.: A Model for Studies of Tropospheric Ozone and Non-Methane Hydrocarbons: Model Evaluation of Ozone Related Species, J. Geophys. Res., 108, 4729, doi:10.1029/2002JD003348, http:// www.mpch-mainz.mpg.de/ $\sim$ kuhlmann/matcheval, 2003b.

Weinheimer, A., Campos, T., Walega, J., Grahek, F., Ridley, B., Baumgardner, D., Twohy, C., Gandrud, B., and Jensen, E.: Uptake of $\mathrm{NO}_{\mathrm{y}}$ on wave-cloud ice particles, Geophys. Res. Lett., 25, 1725-1728, 1998

Zhou, X., Gao, H., He, Y., Huang, G., Bertman, S. B., Civerolo, K., and Schwab, J.: Nitric acid photolysis on surfaces in low- $\mathrm{NO}_{\mathrm{x}}$ environments: Significant atmospheric implications, Geophys. Res. Lett., 30, 2217, doi:10.1029/2003GL018620, 2003.

Ziereis, H., Minikin, A., Schlager, H., Gayet, J. F., Auriol, F., Stock, P., Baehr, J., Petzold, A., Schumann, U., Weinheimer, A., Ridley, B., and Ström, J.: Uptake of reactive nitrogen on cirrus cloud particles during INCA, Geophys. Res. Lett., 31, L05 115, doi:10.1029/2003GL018794, 2004

Zondlo, M. A., Barone, S. B., and Tolbert, M. A.: Uptake of $\mathrm{HNO}_{3}$ on ice under upper tropospheric conditions, Geophys. Res. Lett., 24, 1391-1394, 1997. 